\title{
MUHAMMAD SYAHRUR DAN KONSEP MILKUL YAMIN: KRITIK PENAFSIRAN PERSPEKTIF USHUL FIQH
}

\author{
Mukhammad Nur Hadi \\ Pascasarjana UIN Sunan Kalijaga Yogyakarta \\ hadinurmukhammad@gmail.com
}

Abstract: The Scholars stated that occurring verses of milkul yamin (slave ownership) had been stoped because of its locus which was disappeared. Meanwhile, the trademark of al-Qur'an as the book of revelation which is always relevant unlimitedly to dynamic of era has been paradox. On the other hand, through Syahrur verses of milkul yamin uniquely can be interpreted with the new locus. Syahrur assumed that nowadays the context of milkul yamin can be compared with 'aqdul ihshan (commitment of sexual intercourse) as the way to legitimate sexual intercourse outside marriage that is happening in the Western tradition. This concept was based on sexual intercourse between man and his slave which was taken from three chapters; al-Ahzab: 50, al-Mu'minun: 5-6, and an-Nur: 31 as a consequence of the view of Syahrur's limit theory to the comprehnsive norm of al-Qur'an. However, the problem is that is reinterpretation of Syahrur relevant accordance with the principal orinentation of al-Qur'an (maqashid alQur'an). Ideally, the recontextualization should considered general benefits (mashlahat) for human because not all traditions can be accommodated by Islam. It shows that living Qur'an to verses of milkul yamin on Syharur's perspective ignored the dialectic between mashlahat (benefit) and 'urf (tradition). In this position, reexamining Syharur's thought of his reinterpretation to milkul yamin by considering the ideal of human-social reality does not find base paradigm.

Keywords: Milkul Yamin, Mashlahat, 'Urf

Abstrak: Jumhhur Ulama' menyatakan bahwa pemberlakuan ayat tentang kepemilikan budak (milkul yamin) sudah berhenti karena ketiadaan locusnya.Sementara itu, trademark al-Qur'an sebagai kitab wahyu yang berelevansi tak terbatas dengan zaman menjadi paradoks.Uniknya, di tangan 
Syahrurayat tentang milkul yamin bisa hidup kembali dengan menemukan locus barunya. Syahrur berasumsi bahwa konteks milkul yamin saat ini sama dengan konsep zaujul misyar (nikah wisata/kontrak) yang kemudian diganti dengan istilah aqdul ihshan (komitmen hubungan badan) sebagai bentuk upaya melegitimasi hubungan intim tanpa melalui pernikahan (kumpul kebo) yang masih hidup dalam tradisi sosial masyarakat Barat. Konsep ini berdasar pada adanya interkasi biologis antara tuan dan budakyang diambil dari tiga surat; al-Ahzab: 50, al-Mu'minun: 5-6, dan an-Nur: 31 sebagai konsekuensi logis dari grand teori limitnya.Hal ini karena Syahrur melihat cakupan al Qur'an yang utuh dan menyuluruh (syumuliyyah). Namun permasalahannya adalah apakah upaya reinterpretasi Syahrur tersebut sesuai dengan orientasi pokok al-Qur'an (maqashid al-Quran). Sebab, idealnya segenap usaha rekontekstualisasi hendaknyajuga mempertimbangkan aspek kemaslahatanummat manusia secara keseluruhan. Karena faktanya, tidak semua tradisi dapat diakomodir oleh Islam. Hal ini menunjukkan bahwa living Qur'an dalam ayat milkul yaminperspektifSyahrur tampak abai terhadap dialektika mashlahat dan urf.Pada titik ini, mengkaji kembali pemikiran Muhammad Syahrur yang berkaitan dengan laku interpretative terhadap ayat milkul yamin dengan mempertimbangkan idealitas relasi sosial kemanusiaan tidak menemukan pijakan paradigmatiknya.

Kata Kunci: Mlikul Yamin, Mashlahat, 'Urf

\section{Pendahuluan}

Islam datang membawa misi rahmatan lil 'alamindimana keadaan dunia, wilayah Arab khususnya, saat Islam turun jauh dari relasi kasih sayang. Budaya eskploitasi dan dominasi oleh kelompok yang kuat telah melembaga cukup kuat.Sementara itu, relasi seks suami istri dan selainnya jauh dari standar moral kemanusiaan. Selain itu, budaya kesukuan yang mengakar di masyarakat Arab menyebabkan mudahnya pertumpahan darah antar sesame saudara. Dari sini Islam mengajarkan untuk memahami relasi seksual yang baik dan mengajarkan sikap ta'awun (tolong menolong) antar manusia tanpa memandang perbedaan golongan atau suku. Oleh karena itu, Islam tidak mentolelir budaya eksploitasi dan dominasi yang merendahkan harkat dan martabat manusia sebagai patron awal sikap perikemanusiaan 
yang ideal untuk alam semesta. Hal ini terlihat di beberapa ayat al-Qur'an yang menyuarakan kesetaraan derajat manusia.

Kepemilikan budak (milkul yamin) yang telah melembagaadalah salah satu fokus kritik al-Qur'an terhadap budaya eksploitasi dan dominasi di Arab. Al-Qur'an memandang bahwa hal itu harus segera dieliminasi meskipun dilakukan secara gradual.Selainmelalui kafarat berupa memerdekakan budak, al-Qur'anjuga membolehkan tuan menggauli budak pribadinyasebagaimanatermktub di beberapa ayat sebagai salah satu cara gradual mengeliminasi perbudakan. Tujuannya adalah agar ketika si tuan meninggal dan si budak melahirkan anak dari hasil hubungan badan mereka maka budak tersebut bisa merdeka, (Ahmad Syafiq, 2010: 79)dan demi menepis asumsi mayoritas saat itu bahwa budak akan selamanya menjadi budak. Bahkan, melalui cara ini Islam banyak memerdekakan budak.( Ahmad Sayuti, 2015: 98)

Seiring berjalannya waktu, aturan kebolehan menggauli budak dalam al-Qur'an telah disepakati berhenti oleh Ulama', bukan karena dinaskhtetapi karena ketiadaan locusnya, sebagaimana penjelasan Quraish Sihab. Hal ini diperkuat dengan sejarah penghapusan perbudakan yang dideklarasikan di Prancis dan juga penolakan Abraham Lincon terhadap perbudakan di Amerika.( Abdullah Nashih, 83)Terhadap konsesus ini, Syahrur berasumsi bahwa ayat milkul yamin bisa relevan dengan menganggap zaujul misyar esensinya sama dengan konsep milkul yamin, yaitu ada kesepakatan hubungan biologis tanpa ada tujuan membangun rumah tangga. Untuk itu, menurut Syahrur termzaujul misyar idealnya diganti dengan 'aqdul ihshan (komitmen hubungan badan). Perbedaan cara pandang Syahrur dari pandangan mayoritas menyebabkan Syahrur tampak menyimpang dari orientasi pokok al-Qur'an (maqashidal-Qur'an)yang membuatnya terlihat tidak memiliki pijakan paradigmatik.

\section{Kajian Kritis Terhadap Pemikiran Muhammad Syahrur}

Sejauh ini, kritik terhadap nalar dan hasil ijtihad Syahrur sudah banyak dilakukan oleh berbagai peneliti. Namun, artikel yang berkomentar secara tajam terhadap Syahrurseringkali hanya sekadar mendeskripsikan relevansi dan signifikansi ide-ide kontroversialnya. Alam Tarlam, misalnya, 
mengkritik nalar hermeneutika Syahrur denganmeminjamnalar kritik Yusuf Saidawi yang mengurai kelemahan Syahrur dalam kesusteraannya.(Alam Tarlam, 2015)Kritik yang sama juga dilakukan oleh Syamsul Wathani. Ia mengomentari nalar lingusitik Syahrur dengan memimjam nalar kritik Salim al-Jabi. Sama halnya dengan Alam Tarlam, Syamsul Wathani masih belum menggunakan instrumen hasil pemikirannya untuk mengkritik Syahrur.(Syamsul Wathani, 2018)Kritikan lebih tajam ditulis oleh Qaem Aulassyahied. Tidak seperti dua tulisan sebelumnya, kritik Qaem terhadap Syahrur fokus pada konsep sunnah yang digagas Syahrur. Dengan detail ia menguraikan kerancuan nalar Syahrur dalam menyusun konsep sunnah. Sederhananya, Qaem menyebut Syahrur sebagai pemikir yang inkaru assunnah. (Qaem Aulassyahied, 2015)

Sementara itu, selain munculnya artikel-artikel yang mengkritik Syahrur, banyak juga ditemukan artikel yang justru mengapresasi ide-ide Syahrur yang dianggap aplicable. Ulasan yang disampaikan pun cenderung deskriptif. Abdul Mustaqim, misalnya,berpandangan bahwa teori limit Syahrur itu punya daya progresifitas yang unik dari teori hudud konvensional. Sebabnya adalah pembicaraan teori limit konvensional masih seputar 'uqubat (hukuman) sedangkan teori hudud Syahrurcenderung dinamis-kontekstual yang tidak hanya sekedar membahas 'uqubat.( Abdul Mustaqim, 2017 Hal senada juga dilakukan oleh Sakirman. Ulasan yang ia uraikan di artikelnya hampir sama dengan apayang dilakukan oleh para peneliti pada umumnya; hanya mengurai dan mengkaji bagaimana metodologi teori limit Muhammad Syahrur bekerja.(Sukiman, 2017)

Berbeda dengan genre penelitian sebelumnya, Muhyar Fanani melakukan penelitian terhadap teori hudud Syahrur dengan sudut pandang ilmu ushul figh. Namun, pendekatan yang ia gunakan bukan pendekatan ushuli tetapi berbasis pada pendekatan sosiologi ilmu pengetahuan. Meskipun teori hudud itu berupaya untuk menegakkan supremasi sipil dan demokarasi, bagi Muhyar, teori hudud Syahrur akan mengalami kebuntuan kecuali jika dilengkapi dengan perangkat hermeneutika kritis. Muhyar punya harapan bahwa teori hudud Syahrur bisa bekerja secara maksimal demi menghasilkan teori ushul fiqh progresif.( Muhyar Fanani, 2005)

Sejauh ini, berdasar berbagai penelitian yang ada, kajian kritis secara khusus terhadap konsep milkul yamin kontemporer Syahrur agaknya masih 
belum disentuh secara komprehensif, meskipun kaitan metodologi dari hasil pemikiran berulangkali didiskusikan. Oleh karena itu, penulis memandang bahwa gagasan milkul yamin ini perlu untuk dikaji lebih detail.Dengan menjadikan ushul fikih sebagai perspektif,artikel ini berupaya membedah nalar ijtihad Syahrur terhadap milkul yamin yang dianggap sebagai gagasan pembaharu dalam nalar ushul fiqhmelalui eksplorasi teori mashlahah dan 'urf sekaligus.

\section{Biografi Singkat Muhammad Syahrur}

Muhammad Ibnu Da'ib Syahrur, yang lebih terkenal dengan Muhammad Syahrur lahir pada 11 Maret 1938, di Salihiyyah, salah satu sudut kota Damaskus, Syiria. Meskipun keluarganya adalah Sunni Tulen, Sharur tidak disekolahkan di kuttab atau madrasah yang jelas beraliran sunni tetapi ia justru disekolahkan di sekolah yang menerapkan pendidikan sekular di al-Midan-wilayah bagian selatan pinggiran kota Damaskus.Ini menjadi bukti bahwa sejak kecil Syahrur memang tidak secara intensif atau diintefsikan untuk mendalami keilmuan agama. Setelah menyelesaikan jenjang sekolah menengah pada tahun 1957, Syahrur kemudian pergi ke Moskow,Uni Soviet, untuk belajar teknik sipil dengan beasiswa dari pemetintah. Di sinilah Syahrur banyak mengenaliidelogi Marxisme yang kemudian turut mewarnai pemikirannya. (Muhammad Syahrur, 2009: 19-20)

Usai menamatkan studinya di Moskow 1964, Syahrur kembali ke Syiria dan menjadi pengajar di Universitas Damaskus. Sejaktahun 1968 ia memutuskan untuk melanjutkan studinya di jenjang master hingga doktoral di National University of Ireland. Jenjang master ia selesaikan tahun 1969 dengan konsentrasi Mekanika Tanah, sedangkan jenjang doktoral ia selesaikan tahun 1972 dengan bidang Teknik Pondasi. Usai studinya di Irlandia, selain menjadi pengajar di Universitas Damaskus, Syahrur juga berkiprah pada dunia teknik dengan menjadi konsultan teknik bangunan untuk ribuan bangunan di kota Damaskus. (Muhammad Syahrur, 2009: 20)

Perhatian Syahrur terhadap kajian keIslaman sebenarnya sudah muncul sejak ia studi di Dublin. Dengan kata lain, buku pertama yang dihasilkannya, al-Kitab wa al-Qur'an, adalah hasil pemikirannya yang terus diolahnya selama kurang lebih dua puluh tahun. Nalar kritisnya semakin 
mantap ketika ia mendapat inspirasi saat mengajar tentang bagaimana membuat kontruksi jalan rapat yang juga memakai konsep limitasi maksimal dan minimal. Seketika, ia berfikir bahwa idealnya ada konsep God's Limits. Dari sinilah, ia kemudian menemukan lima kasus di al-Qur'an yang dianggapnya sebagai maksud dari God's Limit.(Muhammad Syahrur, 2009: 11)Lebih lanjut, pengembangan ide teori limitnya semakin menemukan arahnya ketika ia bertemu dengan temannya saat studi di Dublin. Adalah Dr. Jakfar Dakk al-Bab, ahli linguistik, yang kemudian menjadi sumber utama Syahrur untuk menggali dan mengelaborasi pengetahuan linguistik Syahrur yang turut mewarnai dan berpengaruh dalam teori kontemporer hukum Islamnya. (Muhammad Syahrur, 2009: 11)

Secara general, timelineatau tahapanpembentukan nalar kritis pemikiran Syahrur menurut terbagi ke dalam tiga fase. Pertama adalah fase kontemplasi dan peletakan dasar pemahamannya yang terjadi pada tahun 1970-1978 dimana Syahrur belum menghasilkan karya. Ia hanya dalam masa menyadari bahwa metodologi dan peneltian kajian Islam berada pada titik nadir karena masih terbelenggu oleh dikotomi nalar kalam Sunni dan Mu'tazilah serta paradigma fiqh yang didominasi oleh lima mazhab; Hanafi, Maliki, Syafi'I, Hanbali, dan Ja'fari.Kedua adalah fase pengembaraan intelektualnya dalam linguistik dan filologi dengan menyelami pandanganpandangan beberapa tokoh seperti al-Fara', Abu Ali al-Farisi, Ibnu Jinni, alJurjani, dan sebagainya.Pada fase inilah Syahrur bertemu dengan teman yang sekaligus menjadi gurunya, Dr. Ja'far Dikk al-Bab, yang melatari Syahrur menyelami dan menganlisis ayat-ayat al-Qur'an dengan pendekatan baru. Fase ini terjadi pada tahun 1980-1986. Ketiga adalah fase Syahrur Syharur memulai kreatifitasnya dalam mengolah pemikirannya yang terjadi pada tahun 1986-1990. Bab pertama dari buku al-Kitab wa al-Qur'an: Qira'ah Mu'ashirah diselesaikan antara tahun 1986-1987 dan sisanya diselesaikan sampai tahun 1990. (Muhammad Syahrur, 2009: 11)

Sebagai pemikir Muslim Kontemporer, Muhammad Syahrur berhasil menghasilkanbeberapa karya dalam kajian Islam. Selain karya al-Kitab wa al-Qur'an: Qira'ah Mu'ashirah (1990)di antara karyanya yang lain adalah, Dirasat al-Islamiyyah al-Mu'ashihrah fi ad-Dualah wa al-Mujtama'(1994), al-Islam wa al-Iman (1996),Nahwu Ushul Jadidad Lil Fiqhi al-Islami: Fiqhu al-Mar'ah (2000), Tajfifu Manabi'I al-Irhab (2008),al-Qishah al-Qur'aniQira'ah Mu'ashirah I: Madkhal ila al-Qishashi wa al- Qishati Adam (2010), 
dan al-Qishah al-Qur'ani-Qira'ah Mu'ashirah II: Min Nu hila Yusuf (2011). Termsuk karyanya adalah buku yang diedit dan diterjemah oleh Andreas Christman; The Qur'an, Morality, and Critical Reason: The Essential Muhammad Shasrur (2009). Baru-baru ini, Syahrur juga merilis buku barunya,al-Islam wa al-Insan: Min Nataij al-Qir'ah al-Mu'ashirah (2016)yang kemudian diterjemahkan dalam bahasa InggrisIslam and Humanity: Consequence of Contemporary Reading(2017).

\section{Kerangka Teori Umum: Milkul Yamin dalam Perspektif Muhammad Syahrur}

Konstruksiteorimilkul yamin Syahrur tidak bisa terlepas dari grand teori limitnya. Teori limit Syahrur terbangun atas asumsi bahwa risalah Nabi Muhammad SAW adalah risalah universal yang terus relevan, fleksibel, dinamis, dan selalu mutajaddid (terbaharui) sejalan dengan dinamika zaman. Syahrur memandang bahwa sifat pasti dan lurus (istiqamah) dan sifat lentur (hanifiyyah) adalah kunci utama yang harus digunakan untuk memahami risalah Nabi Muhammad SAW. Menurut Syahrur, term istiqamah berasal dari kata qawama yang secara bisa bermakna intishab (tegak, lururs)atau 'azm (kehendak kuat atau kokoh). Term ini berdasar pada beberapa ayat, antara lain Q.S al-Fatihah: 6, al-An'am :153, 161, dan as-Shaffat: 118. Sedangkan term hanifiyyah merupakan derivasi dari kata hanafa yang berarti mail wa inhraf (kecenderungan, pelengkungan, dan pembelokan). Dasar pijakan term ini lebih banyak ditemukan dari pada term istiqamah, antara lain Q.S al-An'am: 79, 161, ar-Rum: 30, al-Bayyinah: 5, al-Hajj: 31, an-Nisa': 125, Yunus: 105, an-Nahl: 120, 123, Ali Imran: 67, 95.

Dengan menginventarisasi ayat-ayat yang bekaitan, Syahrur menemukan bahwa satu-satunya ayat yang menerangkan dialektika sifat istiqamah dan hanifiyyah sebagai karakter agama Islam yang memicu jutaan kemungkinan dalam penetapan hukum yang mencakup seluruh aspek kehidupan manusia di setiap ruang dan waktu adalah Q.S al-An'am: 161. Berdasar pada sifat alam semesta yang selalu dinamis (Q.S al-An'am: 79), Syahrur berargumen bahwa agama yang hanif idealnya selaras dengan sifat alam; lentur, fleksibel dan dinamis. Inilah kemudian yang disebut sebagai sifat perubahan(mutaghayyarat) yang mengandung arti dinamika dan 
progresifitas. Pada titik ini, sifat istiqamah berperan untuk mengarahakan fleksibiltas agama agar menemukan postulat-postulat dasar kehidupan yang telah ditetapkan.

Melalui dialektika dua sifat tersebut, Syahrur barasumsi bahwa hukum Islam akan selalu menemukan relvansinya kapanpun dan dimanapun. Hubungan dilaektis dua sifat tersebut itu menjadi dasar Syahrur dalam mengkonstruk teori limitnya (nadzhariyyahal-hudud) yang berdasar pada Q.S an-Nisa": 13-14. Kalimat "tilka hududullah"pada kedua ayat tersebut bagi Syahrur merupakan sebuah indikasi bahwa yang berotoritas menetapkan batasan-batasan hukum adalah Nabi dan Rasul. Sedangkan nabi Muhammad sendiri hanya sebagai pelopor ijitihad dan tidak memiliki otoritas penuh. Dengan demikian, Syahrur hendak mengatakan bahwa karena hukum-hukum yang dihasilkan Nabi bersfat temporal dan terikat oleh tempat dan waktu, maka manusia masih mempunyai ruang gerak untuk berijtihad lebih lanjut.(Alam Tarlam, 98)

Dengan menggunakan konsep analisis matematika Newton, Syahrur berhasil mengkategorisasi enam wilayah ijtihad berdasar teori limitnya itu. Dengan persamaan $Y=f(x)$ untuk satu variable perubah dan $Y=f(x, z)$ untuk dua variable perubah. Dalam aplikasi teorinya akan muncul bentuk kurva dimana sumbu Y (garis vertikal)melambangkan perkembangan hukum yang selalu dinamis, sedangkan sumbu X (garis horizontal) melambangkan waktu atau konteks sejarah hukum diterapkan. Untuk titik ordinat (O) adalah lambang awal diutusnya Nabi Muhammad saw. Untuk lebih jelasnya, berikut uraian teori limit Syahrur yang terurai dalam enam model teori limit.

Pertama adalahposisi batas minimal (halah hadd al-adna) dengan kurva berbentuk terbuka dimana satu titik balik minimum terletak berhimpit sejajar denga garis sumbu $X$ adalah hasil dari persamaan $y=f(x)$ untuk posisi ini. Dalam posisi ini, penetapan hukum hanya boleh dilakukan di atas batas minimum namun tidak boleh melebihi batas minimum tersebut. Ayat-ayat tentang maharam (an-Nisa': 22-23), tentang makanan yang haram dimakan (al-Maidah: 3), dan juga ayat tentang batasan aurat wanita (an-Nur:31) adalah contoh untuk posisi ini. (Muhammad Syahrur, 452- 455)

Kedua adalah posisi batas maksimal (halah hadd al-a'la) dengan bentuk kurva tertutup dengan garis lengkung mengahadap ke bawah yang merupakan hasil dari persamaan $\mathrm{y}=\mathrm{f}(\mathrm{x}, \mathrm{z})$. Artinya, dalam menetapkan hukum 
tidak boleh melebihi batas maksimal. Ruang ijtihad penetapan hukum berada di bawah batas maksimal atau mungkin berada pas dengan batas maksimal. Contoh untuk posisi ini adalah hukuman potong tangan. Bagi Syahrur, hukum potong tangan adalah hukuman maksimal bagi pencuri sehingga pencuri boleh dihukum selain yang lebih rendah dari potong tangan namun tidak boleh melebihi batas maksimal tersebut (Q.S. al-Maidah: 38). (Muhammad Syahrur, 452- 455)

Ketigaadalah posisi batas minimal dan maksimal bersamaan (halah al-haddain al-a'la wa al-adna ma'an)dengan kurva berbentuk gelombang yang memiliki batas minimal dan maksimal. Titik baliknya berada pada garis lurus yang sejajar dengan sumbu x. Oleh karena itu, pada posisi ini hukum yang ditetapkan memiliki posisi batas minimal dan maksimal secara bersamaam. Konsekuensinya, penetapannya atau ijtihad bisa dilakukan di antara dua batas tersebut. Yang termsuk kategori ini adalah ayat-ayat yang berbicara tentang poligami (an-Nisa':3) dan kewarisan (an-Nisa': 11-14). (Muhammad Syahrur, 452- 455)

Keempatadalah posisi lurus tanpa alternatif (halah al-mustaqim) dengan $y=f(x)$ bernilai konstan untuk semua $x$. Maka, daerah hasil untuk posisi ini hanya berupa garis lurus yang sejajar dengan sumbu $\mathrm{x}$. Konsekuensinya, posisi ini tidak memiliki batas minimal dan maksimal. Sederhananya, hukum yang ditetapkan meskipun zaman telah berubah adalah tetap. Contoh untuk posisi ini adalah hukuman zina muhsan (an-Nur: 2). Bagi Syahrur, hukuman zina tidak bisa dikurangi, karena rasa kasihan, atau ditambah karena ada indikasi kata wala ta'khudzkum.( Muhammad Syahrur, 463)

Kelima adalah posisi batas maksimal tanpa menyentuh garis batas minimal sama sekali (halah al-had al-a'la al-muqarib duna al-mamas bi alhad abadan) dengan hasil persamaan berupa kurva terbuka dimana titik pangkal hampir berhimpit dengan sumbu $\mathrm{x}$ dan titik final hampir berhimpit dengan sumbu $x$. Pada akhirnya, titik final hanya benar-benar berhimpit pada sumbu y di daerah tak terhingga. Untuk posisi ini, contoh yang diberikan Syahrur adalah aturan hubungan atau interaksi antara laki-laki dan perempuan yang mendekati zina. Seseorang tidak boleh melakukan hal-hal yang menjurus kepada zina. Jika sampai berbuat zina, dalam hal ini 
menyentuh garis lurus (mustaqim) sebagai gambaran batasan aturan interaksi, maka hukuman Allah layak dijatuhkan kepadanya. (Muhammad Syahrur, 628)

Keenam adalah posisi batas maksimal positif dan batas minimal negatif (halah al-had al-a'la mujaban wa al-had al-adna saliban)yang hasil persmaannya berupakurva gelombang.Titik balik balik maksimum ada di daerah positif dan titik balik minimum ada di daerah negatif yang kedua titik balik tersebut tidak boleh dilampaui. Kedua titik itu berhimpit dengan garis lurus sejajar sumbu x. Aplikasi teori ini digunakan untuk kasus bunga bank atau riba sebagai batas maksimal yang tidak boleh dilanggar dan kewajiban zakat sebagai batas minimal yang boleh untuk melebihkan bayaran; yang berupa sadaqah. Sedangkan posisi tengah yang disimbolkan dengan titik nol pada persilangan dua sumbu adalah posisi dimana akaqard hasan (pinjaman tanpa bunga) terjadi. ${ }^{1}$

Contoh aplikasi teori limit pada beberapa kasus tersebut hanya bentuk aplikasi dasar teori limitnya. Pada perkembangannya teori ini juga berfungsi pada berbagai ide-ide kreatifnya yang lain. Beberapa contoh aplikasi kontroversialnya yang lain adalah terkait batasan aurat,homosexual, dan milkul yamin dimana semuanya terkesan abai dengan batasan etik urf (tradisi).

Termmilkul yamin telah mengalami perubahan konsep karena adanya perubahan konteks. Syahrur berasumsi bahwa ayat-ayat milkul yamin harus direkontekstualisasi agar tidak mati secara ahitsoris karena fakatanya budak sudah tidak ditemukan. Oleh sebab itu, menurut Syahrur ketetapan dalam termmilkul yamin yang ada harus dipahami secara lebih esensial. Dengan mengacu pada adanyarelasi seksual antara tuan dan budak, yang terekam pada beberapa ayat; al-Ahzab: 50, al-Mu'minun: 5-6, dan an-Nur: 31, Syahrur berasumsi bahwarelasi sesksual itulah yang menjadi core konsep milkul yamin kontemporer. Syahrur memandang bahwa ayat tentang milkul yamin mengindikasikan adanya perbedaan status hubungan badan antara suami dengan istri dan suami dengan milkul yamin. Namun, pada intinya perbedaan status hubungan itu bertemu pada satu titik, yaitu hubungan kelamin.Lebih dari itu, Syahrur memandang bahwa relasi seksual tersebut tidak ada unsur atau tujuan untuk membangun rumah tangga melainkan hanya sekedar melampiaskan nafsu seksual. Bagi Syahrur, kasus ini sama

\footnotetext{
${ }^{1}$ Ibid.,hlm. 465 .
} 
dengan konsep zawjul misyar yang menurutnya terjadi karena ada keinginan atau hasrat seksualitas di antara laki-laki dan perempuan. Oleh sebab itu, konsep milkul yamin kontemporer lebih tepat jika dimaknai dengan 'aqdul ihshan (komitmen hubungan seksual). ${ }^{2}$

\section{Paradigma Ijtihad Konsep Milkul Yamin Muhammad Sharur}

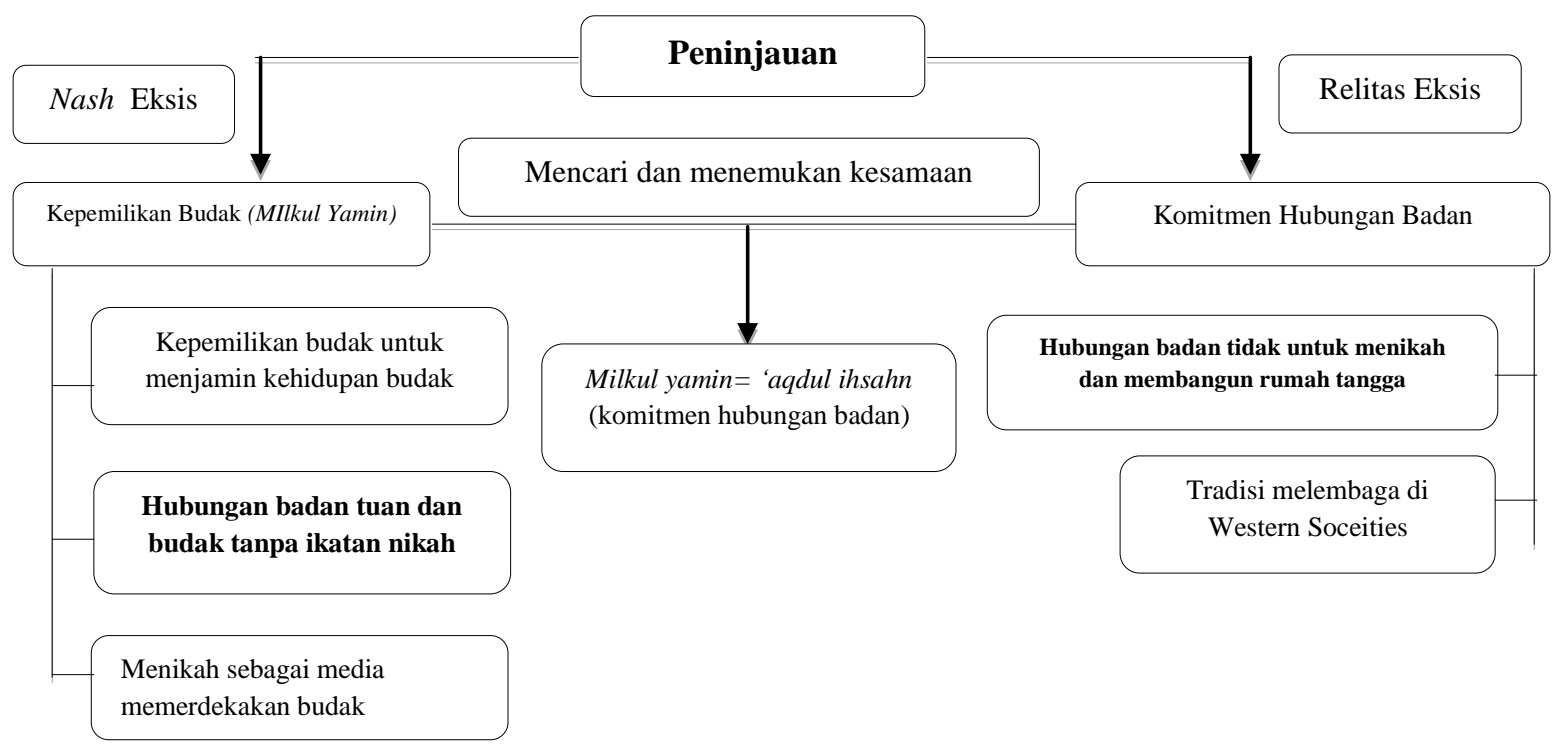

Anggapan Syahrur tentang milkul yamin kontemporer sama dengan hasil aplikasi teori limit Syahrur yang tampak pada kasus zina yang dilakukan secara tertutup. Bagi Syahrur, publik tidak berhak untuk memvonis dan menjatuhkan hukuman bagi mereka yang melakukan zina dengan tidak terang-terangan karena hal itu adalah ranah relasi pelaku dengan Tuhannya. (Muhammad Syahrur, 2009: 628)Pada tataran ini, Syahrur juga tampak tidak mempermasalahkan adanya prostitusi, karena prositusi juga dilakukan di tempat tertutup, atau hubungan gelap.Dengan pijakan teorihad al-a 'la (batas maksimal), hubungan badan yang juga bisa terjadi karena adanya komitmen hubungan seksual bisa masuk batas maksimal ketika diketahui oleh orang lain atau dilakukan secara terang-terangan. Sesuai dengan nalar teori

\footnotetext{
${ }^{2}$ Muhammad Syahrur, Nahwu Ushul Jadidah lil Fiqh al-Islamy: Fiqhu al-Mar'ah, cet. ke-1 (Damaskus: al-Ahali, 2000), hlm. 308.
} 
limitnya, seseorang yang menjalin hubungan seksual atau komitmen hubungan di luar nikah tidak bisa diberi hukuman selama tidak ada empat saksi yang menyaksikannya secara langsung.Bahkan dalam kasus ini, hubungan intim sesama jenis pun (homosexual intercourse) bisa dianggap layak untuk tidak mendapat hukuman selama para pelaku homoseksual tidak melakukan hubungan seks di depan publik.( Muhammad Syahrur, 2009: 204)

Dari dua contoh aplikasi tersebut, paradigma teori limit Syahrur patut dicurigai karena terlihat melawan konsep mashlahat. Secara lebih detail, interpretasiSyahrur terhadap milkul yaminbertolak belakang dengan konsep teori limit halah al-had al-a'la al-muqarib duna al-mamas bi al-had abadan (batas maksimal tanpa menyentuh garis batas minimal sama sekali). Pada teori iniSyahrur menguraikan bahwa seseorang tidak boleh melakukan segala bentuk relasi sosial yang mendekati hubungan seksual. Namun faktanya, Syahrur melegitimasi hubungan badan di luar nikah dengan penafsiran milkul yaminnya. Sebagai pemikir Muslim kontemporer, Syahrur terkesan abai terhadap posisi 'urf (tradisi) yang idelanya menjadi pertimbangan penting bagi setipa pemikir Muslim dalam merekontkstualisasi hukum. Pada posisi ini, teori limit Syahrur terlihat tidak memiliki standar kemaslahatan yang ingin dicapai. Lebih jauh lagi, grand teori limit Syahrur juga tampak abai akan akomodasi nash terhadap urf yang membawa kemaslahatan. Jika memang Syahrur dianggap sebagai pembaharu ushul fiq-sebagaimana asumsi Wael Hallaq-,idealnya konsep yang ia konstruk harus memiliki standar kemaslahatan dan tradisi yang jelas.

\section{Dialektika Urf dan Maslahat: Kritik Konsep Milkul Yamin Muhammad Syahrur}

Legitimasi Syahrur terhadap komitmen hubungan badan merujuk pada tiga surat yang mengandung termmilkul yamin, yaitu surat alMu'minun: 5-6, an-Nur: 31, dan al-Ahzab: 50.Untuk membedah nalar ijtihad Syahrur terhadap konsep milkul yamin, kiranya cukup penting untuk membedah kembali interpretasi ulama' tafsir otoritatif.

a) Al-Mu'imun ayat 5-6 


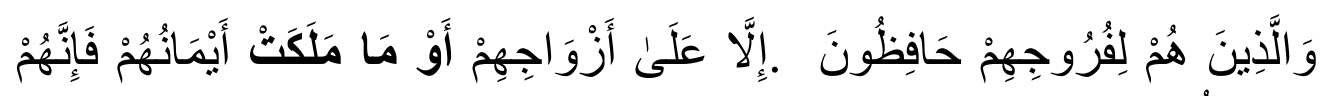 غَبْرُ مَلُو مِينَ}

Dua ayat ini mendeskripsikan salah satu indikasi orang beriman, yaitu orang-orang yang selalu menjaga kemaluannya dari perilaku harambahkan mendekati pun mereka tidak-, kecuali pada pasangan atau istri mereka dan budak mereka yang diperoleh dari tawanan perang- itupun hanya berlaku pada peperangan membela agama. Kebolehan itu berlaku ketika dahulu perbudakan masih melembaga. Berbeda halnya dengan kondisi saat ini dimana perbudakan sudah tidak eksis lagi.(Wahbah Zuhaili, 2009: 331)

Quraish Shihab berpandangan bahwa konteks ayat ini merujuk pada masyarakat yang ketika al-Qur'an diturunkan perbudakan menjadi fenomena umum masyarakat seluruh dunia.Turunnya ayat ini idealnya dipahami sebagai cara gradual al Qur'an untuk menghapus perbudakan. Al Qur'an memahami bahwa kehidupan para budak saat itu, baik sandang, pangan, dan papan, tergantung pada tuannya. Oleh karena itu, ketika al Qur'an memilih memangkas perbudakan secara langsung bisa dipastikan akan terjadi problem sosial yang mungkin bisa lebih jauh dari PHK. Dengan dasar inilah al-Qur'an, pada ayat ini, melegitimasi kebolehan tuan menggauli budaknya sebagai langkah baru mengeliminasi perbudakan. Karena jika budak dinikahi sesama budak, anak yang terlahir juga akan tetap menjadi budak. Kondisi demikian akan terhenti ketika tuan mengawini budaknya karena tradisinya anak yang lahir hasil dari hubungan intim tuan dan budak tidak bisa dikategorikan sebagai budak. Namun, ketika kemudian perbudakan dihapuskan, bukan berarti ayat ini dianggap irrelevan karena faktanya al Qur'an tidak hanya mengatur konteks dimana al-Qur'an turun tetapi ia juga mengatur segala kemungkinan yang tidak terprediksi di masa depan. Melalui dua ayat ini, alQur'an juga ingin menegaskan bahwa Islam tidak memandang seks sebagai sesuatu yang kotor jika ia disalurkan melalui relasi yang legal, karena seks adalah kebutuhan fitrah manusia.( Quraish Shihab, 2009: 326)Dengan demikian, menggauli budak tanpa perlu akad perkawinan bukanlah sesuatu yang hina. Namun, al Qur'an justru memandangnya sebagai sebuah langkah yang perlu dilegitimasi untuk menghentikan 
perbudakan sebagai konsekuensi logis dari pelembagaan perbudakan yang cukup kuat di dunia Arab.

b) An-Nur ayat 31

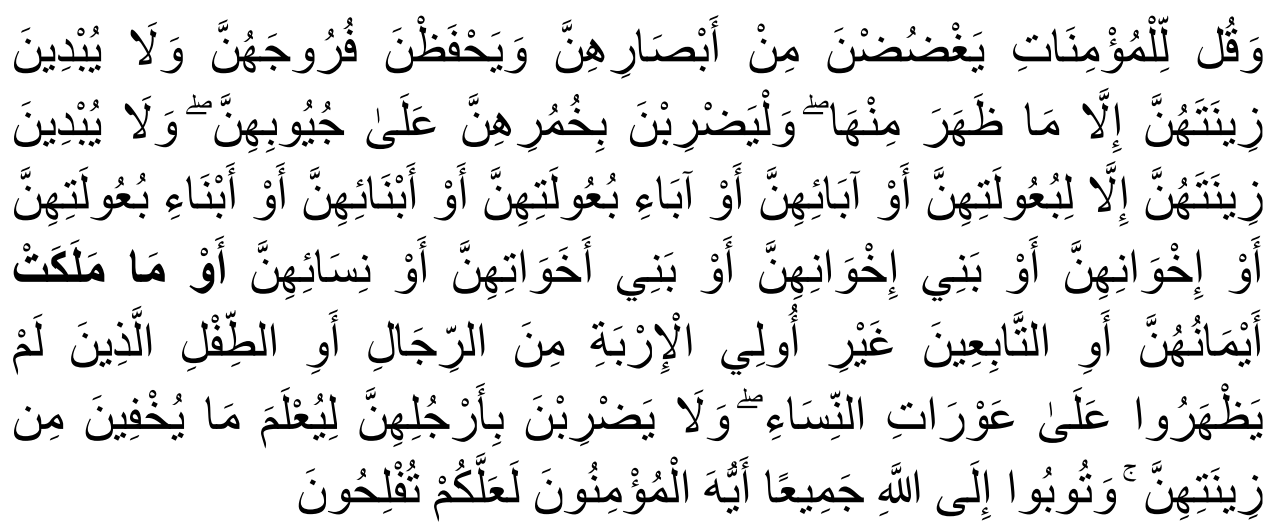

Pembahasan terhadap siapa sajakah wanita boleh memamerkan auratnya merupakan fokus kedua pembahasan pada ayat ini, selain pَrintah menundukkan pandangan dan menjaga kemaluannya.Kalimat مَلَكَتْ أَيْمَانُهُهنَّ dalam ayat ini tidak mengindikasikan kebolehan menggauli budak karena konteks ayat ini membincang tentang batasan-batasan aurat yang boleh ditampakkan oleh seorang wanita.Ayat ini mengutarakan bahwa seluruh tubuh perempuan boleh ditampakkan kepada siapa saja yang telah dilegitimasi oleh al Qur'an, kecuali bagian antara pusar dan lutut.Oleh sebab itu, karena umumnya masyarakat memiliki budak, tidak menjadi masalah untuk menampakkan bagian yang diperbolehkan itu kepada budak laki-laki atau perempuan miliknya.( Wahbah az-Zuhaili, atTafsir al-Munir, 553)Hal ini karena pada umumnya kewibawaan seorang tuan pemilik budak menghalangi para budaknya untuk berlaku usil. (Quraish Shihab, 527)

c) Al-Ahzab: 50

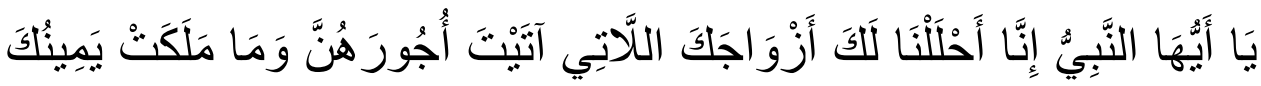

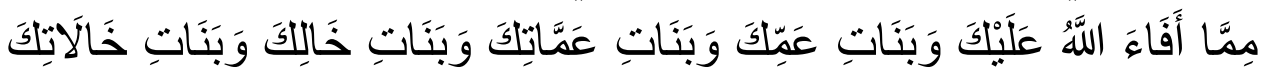

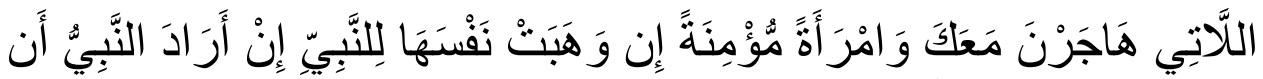

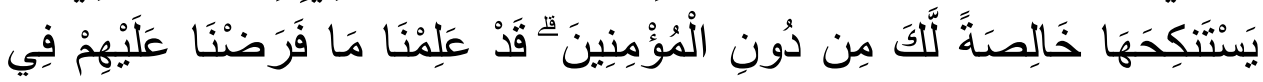




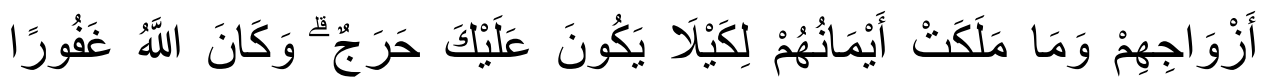

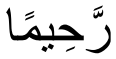

Maksud مَوَمَاdalam ayat ini merujuk pada istri-istri Nabi Muhammad yang berasal dari golongan budak.Poin pentingnya adalah bahwa Nabi Muhammad tidak menggauli mereka saat berstatus budak, melainkan beliau justru memerdekakan mereka terlebih dahulusebelum menjadi istrinya. Bahkan ada juga yang kemerdekaannya sebagai mahar pernikahannya.Menurut Quraish Shihab, konteks ayat menyebut beberapa nama istri Nabi yang berasal dari budak, yaitu Shafiyyah binti Huyai, Juwairiyah binti al-Harits, dan Raihanah alQuraizhah, sebagaimana pendapat al-Biqa'i. Bahkan, menurut Ibnu 'Asyur,istri Nabi yang juga masuk dalam cakupan ayat ini adalah Mariyah al-Qibtiyyah yang merupakan hadiah dari Penguasa Mesir dimana melalui rahim Mariyah Ibrahim dilahirkan. (Quraish Shihab, 513)

Berdasar pada interpretasi ayat-ayat di atas, maka cukup jelas bahwa termmilkul yamin menurut pakar tafsir yang otoritatif tidak hanya melegitimasi kasus hubungan badan yang hanya terbangun berdasar pada komitmen atau perjanjian.Akan tetapi, secara general, ayat ini berbicara mengenai bagaimana al-Qur'an mengeliminasi perbudakan yang terfasilitasi melalui legitimasi persetubuhan terhadap budak.Lalu, apakah penafsiran tersebut dapat dimaknai secara berbeda karena ketiadaan konteksnya atau, apakah penafsiran tersebut belum bersifat syumuliy(menyeluruh).

Dengan penafsirannya yang memaksa untuk menemukan konteks, Syahrur berusaha untuk menghidupkan ayat-ayat milkul yamin itu bagi orang-orang yang berada di negara-negara yang terdominasi oleh nonMuslim.Berdasar pada sifat kesyumuliyyahan al-Qur'an, Syahrur menganggap bahwa orang-orang yang hidup di luar bumi Makkah dan Madinah, seperti di Paris, Tokyo, Montreal, dan sejenisnya, idealnya juga bisamerasakan risalah al-Qur'an yang syumul. (Quraish Shihab, 513)Dengan aplikasi yang lebih luas tersebut, Syahrur memandang bahwadengan memperluas dan mereinterpretasi ayat milkul yamin kesyumuliyahan alQu'ran dapat terealisasi. 
Terhadap sifat syumuliyyah al-Qur'an, rekontekstuliasi hukum Islam menjadisebuah keniscayaan yang harus dilestarikan.Demi menjaga norma dasar Islam, elan vital syari'ah yang terinterpretasi melalui al-Qur'an dan hadits adalah mewujudkan kemaslahatan. Semua aturan tentangnya selalu compatible dan selalu mengandung unsur kemaslahatan. Oleh karenanya, tidak ada satupun hukum atau aturan yang ditetapkan tidak memiliki solusi. Semua yang telah diciptakan dan ditentukan selalu disiapkan olehNya jalan untuk menuju atau meraihnya, bahkan solusi penyelesaiannya. (Ahmad arRaisuni, 2000:29)Namun, apakah kemaslahatan itu juga mewujud dalam interpretasi milkul yamin Syahrur adalah pertanyaan yang akan dijawab dalam tulisan ini.

Ahmad ar-Raisuni berpendapat bahwa merespon semua nash syara' dengan orientasi dan penerapan berbasis mashlahah adalah sebuah keharusan. Cara inilah yang mampu untuk menjawab asumsi-asumsi ketidakberdayaan nash terhadap mashlahah. Bahwa adanya kontradiksi nash atau kenihilan nash akan mashlahah merupakan asumsi yang tidak berdasar. (Ahmad ar-Raisuni, 2000:29) Pandangan yang terakhir ini nampaknya, bagi Syahrur, dijadikan pijakan untuk merealisasikan kemaslahatanmilkul yamin bagi masyarakat dunia Barat yang tradisinya tidak secara implisit terjelaskan dalam al-Qur'an. Syahrur juga tampak memahami bahwa ada legitimasi tentang tradisi komitmen hubungan badan di al-Qur'an melalui termmilkul yamin itu.Akan tetapi, kemaslahatan yang dipahami Syahrur perlu diuji ulang. Posisi dan urgensi maslahat yang ia bangun harus dibedah hingga akarpijakannya. Dengan melihat pada tradisi hidup di dunia Barat, maka pada konteks inikemaslahatan yang diusung Syahrur hanya berpijak pada eksistensi urf (tradisi) di ranah lokalitas, bukan general (syumuliy). Padahal, konstruk gagasan yang ia bangun berusaha untuk merealisasikan kesyumuliyyahan al-Qur'an.

Dalam diskursus fikih, realitasnya 'urfterwujud karena adanya proses dialektis di dalam masyarakat dengan ragam level sosial.Wujudnya dialektika yang terus menerus itu memotivasi Abdul Wahab Khalaf untuk memaknai 'urf sebagai sesuatu yang dikenal manusia dan dijalankan secara biasa, baik berupa perkataan ataupun perbuatan.(Wahab Khalaf, 1972: 145)Untuk lebih memperjelas posisi dan jangkauan 'urf, Ahmad Fahmi Abu Sunnahmendefinisikan "urf dengan menampilkan batasan yang harus dipenuhi. Menurutnya, 'urf bisa diterima jika ia diterima secara rasional (akal 
sehat).( Ahmad Fahmi Abu Sunah, 1947: 8)Dengan begitu, 'urf dalam kajian ushul fiqh tidak mengakomodir kebiasaan yang negatif atau kebiasaan yang tertolak akal sehat(irrational tradition).

Asumsi menafikan 'urf sebagai bentuk eksistensi agama tidak dapat dibenarkan. Sebab agama itu dikenal melalui kenabian. Sedangkan kenabian bisa dikenali melalui mukjizat dimana mukjizat muncul atau terjadi di luar adat atau kebiasaan manusia yang berlaku saat itu. Nabi Muhammad saw pun juga tidak menolak'urf seketika. Akan tetapi, beliau juga melakukan seleksi 'urf dimana'urf yang sesuai dengan ajaran Islam dilanjutkan dan sebaliknya ditinggalkan. Sebab, Nabi sadar bahwa akomodasi urf adalah salah satu cara untuk menguatkan ajaran agama yang masih baru. Oleh karena itusebagaiamana pernyataan Syathibi dalam Muwaqafatbahwa- tidak mengakui adat sama halnya dengan tidak menganggap luhur hal-hal unik yang terjadi di luar kebiasaan;termsuk mukjizat, sebagai realitas yang eksis. Dengan demikian, adanya kesepakatan-kesepakatan yang dihasilkan untuk mewujdukan kemaslahatan untuk dipedomani bersama yang dihasilkan dari diealektika relasi sosial terlimitasi oleh ground norm agama yang juga mencakup batasan etik atau moral kemaslahatan yang dibawa oleh Syari'at Islam melalui nash tentunya juga selaras dengan moralitas kemanusiaan (akhlaqiyyah). Tujuannya adalah untuk menegakkan tatanan sosial dan berusaha untuk mengangkat derajat manusia dan membantu manusia untuk terbebas dari belenggu egoisme serta kebudayaan yang merusak dan pengetahuan yang menyesatkan.(Yusuf Qardawi, 2018: 104)

Dengan penjelasan yang lebih sederhana, proses dialektika relasi sosial yang mewujudkan tradisi dapat disebut sebagai sebuah intsrumen pembentuk hukum. Syekh Ali Jum'ah mengatakan bahwa 'urf merupakan instrumen yang sangat dibutuhkan untuk menyempurnakan penerapan syari'at yang baik dan sempurna yang tentu mengandung aspek kemaslahatan. Meskipun 'urf tidak memunculkan hukum dengan sendirinya, akan tetapi dengan memperhatikan 'urf yang berfungsi sebagai instrumen maksud Syari' akan mudah dicapai.( Ali Jum'ah, 2015: 121)Sehingga, melalui alur ini, dapat dipahami bahwa eksistensi 'urf sejak masa pewahyuan berperan penting sebagai instrumen pembentuk hukum Islam yang akomodatif.( Sunan Autad Sarjana, 2017: 290) 
Aktualisasi ide Syahrur dalam mengakomodir budaya komitmen hubungan badan di dunia Barat, secara rasional, tidak menyalahi pra syarat minimal keberlakuan urf, yaitu ketetapan (istiqrar) dan kontinuitas (istimrar).Istiqrar adalah bentuk kesepakatan antara para pelaku 'urf di ranah lokalitas; makro maupun mikro. Selain ada bentuk kesepakatan, istimrar (kontinuitas) harus mewujud agar bisa dijadikan pedoman hukum yang memadai dan berubah.( M. Noor Harisuddin, 2016) Tentu, ketika salah satu dari kedua unsur ini tidak ada, maka kelayakan urf sebagai pedoman hukum patut dipertanyakan. Namun, Syahrur masih terlihat tidak memahami batasan rasional urf, sebagaimana statement Ahmad Fahmi Abu Sunah. Oleh karena itu, pada titik ini, meskipun Syahrur berupaya untuk merangkul tradisi sosial yang hidup di masyarakat Barat dengan berbasis tradisi berbasis kesepakatan (urf qauli dan amali) yang terikat dengan territorial dan waktu (urf amm dan urf khash), konstruksi nalar kritisnya untuk mengakomodir urf terlihat abai pada kategorisasi urf berbasis kelayakan. Sehingga, validasi kelayakanurf itu tidak terdeteksi.Artinya, dalam membangun teorinya Syahrur tidak memiliki pijakan dan batasan etik atau moral (akhlaqiyyah.

Syahrur menerima pandangan mayoritas bahwa milkul yamin yang dipahami sebagai kepemilikan budak tidak relevan dengan 'urf 'amm yang dipahami mayoritas penduduk dunia yang menyepakatai bahwa milkul yamin (kepemilikan budak) untuk dieksploitasi bertentangan dengan perikemanusiaan era modern.Namun, Syahrur tampak memahami bahwa ada 'urf 'ammlainyang bisa mewakili termmilkul yamin dalam al-Qur'an, yaitu aqdul ihshan (komitmen hubungan badan).Padahal, jika didialektikan dengan konsep umum, komitmen hubungan badan tidak terstandarisasi oleh pandangan mayoritas penduduk dunia.Artinya, 'urf 'amm internasional dapat dikatakan tidak menjalankan budaya aqdul ihshan sebagai realitas relasi sesksual di masyarakat karena ini akan berdampak pada tanggung jawab terhadap anak yang akan dilahirkan dari hubungan itu. Dengan kata lain, anak akan mudah terabaikan haknya karena ketiadaan hubungan nasab yang resmi untuk memunculkan konsekuensi relasi anak dan orang tua. Oleh sebab itu, jika alasan menjaga kehormatan dariaqdul ihshan-sebagaimana persepsi para pelaku-sebagai alasan penguat maksud nash terkait milkul yamin, maka alasan itu sendiri yang sesungguhnya tidak merealisasikan maksud nash untuk menjaga kehormatan (hifdzu al-'irdh). 
Untuk lebih menguatkan, gagasan syekh Said Ramadhan al-Buthi dalam bukunya; Dhawabit al-Mashlahah fi asy-Syari'ah al-Islamiyyah, bisa memperjelas limitasi kemaslahatan terhadap segala tradisi yang ingin dilegitimasi. Berbeda halnya dengan definisi yang dijelaskan oleh Ahmad Fahmi Abu Sunnah yang hanya membatasi kemaslahatan urf sesuai dengan rasionalitas,Al-Buthi berpendapat bahwa, sebagaimana pendapat al-Ghazali, sesuatu, termsuk 'urf, bisa dikatakan megandung mashlahah jika mencakup perlindung terhadap lima tujuan penting (maqasid syari'ah), yaitu penjagaan terhadap agama, jiwa, akal, keterunan dan harta. Secara lebih rinci, al-Buthi memandang perlu adanya batasan kapan sesuatu yang mengandung mashlahah itu bisa divalidasi. Bagi al-Buthi, ada lima standar bagi mashlahat agar bisa dijadikan pedoman hukum, yaitu; (1) masuk dalam cakupan maqashid Syari'ah, (Muhammad at-Thahir Ibnu 'Asyur, 2005).(2) tidak bertentangan dengan al-Qur'an,( Wahbah az-Zuahaili, 1986).(3) tidak bertentangan dengan sunnah, (4) tidak bertentangan dengan qiyas (karena qiyas adalah media untuk mewujudkan mashlahah dalam far'un)(Said Ramadhan al-Buthi, 229-259.)(5)tidak bertentangan dengankemaslahatan lain; baik dari segi kepentingannya (level kebutuhan), kemenyeluruhannya, dan kekuatannya.( al-Buthi lihat di Said Ramadhan al-Buthi, 131-336)

Berdasar padadhawabit al-mashlahahdi atas, konsep milkul yamin Syahrur tidak memenuhi lima standar kemaslahatan dalam syari'ah. Dengan gagasan milkul yaminnya, Syahrur terlihat menabrak batas ground norm syari'ah yang jelas mengandung kemahslahatan lebih besar dalam hal batasan relasi sosial dan relasi biologis yang ditetapkan oleh nashyang kemudian diperjelas dan diperkuat dengan hadits Nabi, yaitu melalui perkawinan. Instrumen ini sebagai bukti bahwa al-Qur'an tidak menganggap kotor sebuah hubungan seksual asalkan secara sah.Selanjutnya, seandainya Syahrur mengklaim bernalar berdasar qiyas, nalar itu pun tidak sesuai dengan nalar qiyas jumhur ulama. Jika jumhur ulama' dalam menggunakan qiyas menentukan komponen penting;ushul, furu', hukmu al-ashl, dan 'illat, Syahrur justru sebaliknya. Ia secara tidak jelas menggunakan metodologi nalar qiyas, meskipun ia telah berusaha mencari padanan kasus untuk dipertemukan kesamaan esensinya. Sehingga, upaya Syahrur untuk memproteksi kasus hukum yang ada pada 'urf tidak menunjukkan pijakan paradigmatiknya. 
Oleh sebab itu, kesepakatan ulama' terkait 'urf manakah yang dianggap sebagai instrumen yang valid agar tidak terjadi klaim urf shahih telah terlimitasi dengan baik dan sistematismelalui standarisasimashlahat alButhi. Jika kemudian alasan hifdzul 'irdhi (menajaga kehormatan) dijadikan pijakanoleh Syahrur, tetap saja konsep itu tidak mencakup nilai dasar yang lain karena status nasab anak yang lahir di luar akad nikah yang sah (children born out of wedlock) akhirnya menjadi polemik dalam persepktif hukum Islam. Konsekuensinya, ketika hal ini diabaikan akan muncul kekaburan garis keturunan beruntun hingga polemikkewarisan. Alasan Maka,meskipun'urf itu telah menyeluruh dan konstan, masih konsisten saat ditetapkan sebagai sumber hukum, dan tidak mengindikasikan adanya perilaku atau ucapan yang bertentangan dengan nilai-nilai substansial adat, namun ia telah menabrak ground norm nash yang mengandung kemaslahatan maka urf itu sudah dianggap cacat secara keseluruhan.(Wahbah al-Zuhayli, 1986: 828)

Berpijak pada uraian di atas, tampak jelas bahwa urf yang diusung oleh Syahrur sebagai objek reinterpretasi ayat tentang milkul yamin tidak memenuhi standar kelayakan maslahat.Dengan kata lain, urf yang dilegitimasi Syahrur adalah 'urf fasid (tradisi yang cacat/tertolak). Maka tepatlah apa yang disampaikan oleh Ibnu Asyur, sebagaimana dinukil oleh Quraish Shihab, bahwa adat kebiasaan suatu kaum tidak boleh-dalam kedudukannya seabagi adat-untuk dipaksakan terhadap kaum lain atas nama agama, bahkan juga tidak dapat dipaksakan terhadap kaum itu.(Quraish Shiab, 533)

Untuk mewujudkan yang demikian itu, maka perlu digagas ijtihad berbasis maslahat yang dikenal dengan ijtihad istishlahy.Ijtihad ini umunya dipahami sebagai usaha untuk memahami nash terhadap kasus tertentu yang tujuan akhirnya berupaya untuk lebih mengutamakan kemaslahatan dimana umumnya digunakan untuk kasus yang belum diakomodir secara jelas dalam nash. Namun, kenyatannya ijtihad ini juga menyentuh pada kasus-kasus yang sudah diatur oleh nash. Contoh yang paling populer untuk hal ini adalah ijtihad Umar bin Khattab terhadap penetapan mengucapkan talak tiga sekaligus sebagai talak satu, penghentian hukuman potong tangan bagi pencuri, dan peghentian pemberian zakat kepada muallaf. Usaha ini dipahami oleh ulama bukan sebagai bentuk meangabaikan nash, tetapi sebagai upaya menghasilkan kemaslahatan dalam konteks kenegaraan (kemaslahatan 
publik).(al-Buthi, 152-175) Apalagi, kualitas Umar bin Khattab sebagai pemegang otoritas ijtihad sangat diakui. Pola yang demikian ini, sebagaimana dijelaskan oleh Asmawi dengan mengutip pendapat Ahmad Fathi Bahnasi, berlanjut danmunculkembali pada generasi al-tabi'in, meskipun hanya sebagian. Kekhawatiran mereka terhadap eliminasi mashahat mengharuskan mereka untuk memilih berpaling dari model penalaran tekstual; nash Syara', baik yang bersifat mutlak atau umum, ke model penalaran yang berbasis mashlahat.(Asmawi, 2014)

Ahmad ar-Raisuni berpendapat bahwa merespon semua nash syara' dengan orientasi dan penerapan berbasis mashlahah adalah sebuah keharusan. Cara inilah yang mampu untuk menjawab asumsi-asumsi ketidakberdayaan nash terhadap mashlahah. Bahwa adanya kontradiksi nash dengan mashlahah atau kenihilan nash akan mashlahah adalah asumsi yang tidak berdasar.( Ahmad ar-Raisuni, 2000: 51)Konsepsi terhadap mashlahat sesungguhnya tidak bisa terlepas dari 'urfkarena'urfadalah komponen penting dalam merekontekstualisasi atau merelevansikan hukum. Ketika 'urf diabaikan, akan ada pertentangan terhadap hasil ijtihad baru. Begitu pula, ketika mashlahat terprioritaskan daripada 'urf atau sebaliknya, tanpa ada upaya dilaketika keduanya, chaos pun akan sulit terhindari. Prinsipnya, kemaslahatan yang dihasilkan harus bisa mengakomodir 'urf dan 'urf yang diterima harus terstandarisasi oleh mashlahat. Dengan kata lain, 'urf yang dianggap membawa kemaslahatan adalah 'urf shahih, yang sesuai dengan apa yang diharapkan oleh nash, ekspilist maupun implisit. Sebab itulah dalam berijtihad dibutuhkan batasan etik atau moral yang jelas. Berikut bagan yang bisa menggambarkan bagaimana nalar reinterpretasi nash berbasis mashlahahdan 'urf(ijtihad itishlahi) secara general, khususnya terkait milkul yamin. 


\section{Paradigma Ideal Rekontekstualisasi Nash Milkul Yamin}

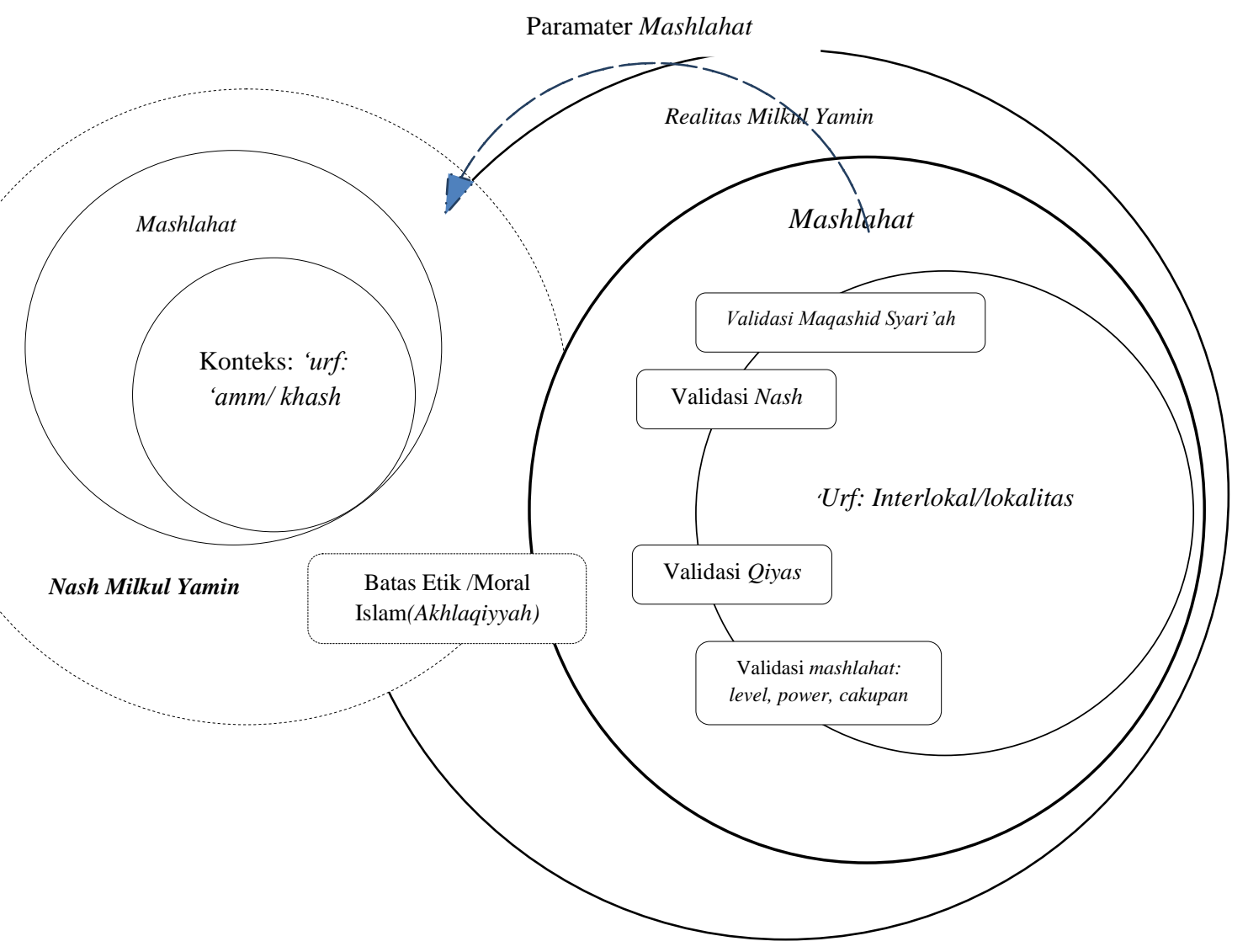

Arena Ijtihad Istishlahi

'areinterpretasi Syahrur terhadap nash milkul yamin idealnya mengikuti dialektika urf dan mashlahat dengan semangat mendialogkan nash dengan realitas sebagai buktidinamika kandungan al-Qur'an. Dengan pola seperti itu, aspek kehidupan yang selalu dinamis tidak akanbersandar pada produk hukum yang statis.(Sunan Autad Sarjana, 289)Karena menstagnasi hukum al-Qur'an sama halnya dengan menganggap al-Qur'an sebagai kitab yang irrasional-irrelevan. Di sisi lain, wujudnya pertimbangan moralitas atau etik, sebagaimana terkonstruk pada gambar, itu pada saatnya akan selalu memandu manusia agar tidak berperilaku yang cenderung destruktif terhadap kandungan-kandungan kemaslahatan yang dibawa oleh nash. Ketika destruktifitas terjadi dengan 
berlandaskan asas kemaslahatan pada nash, maka anggapan yang demikian itu seseungguhnya telah menciderai peran mashlahah yang idealnya memelihara, memperhatikan, dan merelaisasikan tujuan-tujuan nash; berupa kebaikan dan kemanfaatan, yang terkandung dalam nash. Karena itulah, landasan etik atau moral penting untuk diperhatikan agar hasil rekontekstualisasi nash milkul yamin tidak mendekonstruksimashlahah dalam nash.

Produk ijtihad idealnya bisa mengimbangi dinamika realitas sosial sebagai wujud dari esensi hukum Islam yang selalu berdinamika. Namun, bukan berarti produk hukum yang dihasilkan harus terdominasi atau tertundukkan realitas sehingga idealnya yang menagkomodir adalah fikih sebagai produk ijtihad dengan segala norma yang sangat asasi, bukan fikih yang terakomodir oleh realitas sebagaimana yang dilakukan oleh Syahrur. Jika fikih dipaksakan untuk masuk dalam realitas maka pemahaman demikian ini bisa disebut sebagai paham yang tidak berfikih.(Ahmad arRaisuni, 64) Karena sebab ijtihad yang serampangan, produk hukum yang dihasilkan bukan merepresentasikan ground norm Islam tetapi produk hukum yang lebih tampak mengatur adalah produk yang bernuansa hawa nafsu sehingga hukum yang semula berusaha untuk mengatur manusia untuk bisa lebih dekat kepada Tuhan-Nya berubah kepada hukum yang justru hanya memuaskan keinginan atau tuntutan kehidupan manusia.

Untuk itulah, sebagai ulasan akhir artikel ini, sebagaimana tergambar pada bagan bahwagagasan Ahmad ar-Raisuni tentang bagaimana kualifikasi mashlahah dengan parameter nashdapat menjadi pijakan penting bagi siapapun yang hendak berijithad berbasis mashlahah (ijtihad istihslahi). Dengan merujuk pada surat al-Anbiya' ayat 107-“Kami tidak menurunkanmu (Nabi Muhammad) kecuali hanya sebagai rahmat untuk alam semesta"- arRaisuni berpandangan bahwa nashmengandung nilai keadilan, rahmat, dan mashlahat. Tetapi bukan berarti dengan asumsi demikian, dalam nashbisa ditemukan jawaban yang memerinci dan membatasi secara detail bagaimana mashlahah dan mafsadah yang idealnya menjadi pedoman. Kuncinya adalah bahwa nash diposisikan sebagai parameter untuk mengidentifikasi mashlahah, memetakan mashlahah dan mafsadah, dan mengkategorisasi level mashlahat dari segi kebutuhan maupun cakupannya.(Ahmad ar-Raisuni, 50) Dengan memahami positioning (penempatan) nash, seorang mujtahid 
akan terhindar dari alur nalar yang cenderung menundukan fikih di bawah rasio; sebagaimana yang dipraktikkan oleh Syahrur, sehingga destruktifitas groundnorm nash tidak terjadi.

\section{PENUTUP}

Reinterpretasinashterkait milkul yamin oleh Muhammad Syahrur dengan pertimbangan realitas yang eksis, komitmen hubungan badan pada masyarakat Barat, menunjukkan kecacatan paradigmanya. Kesamaan esensi realitas sosial yang telah mentradisi di dunia Barat (komitmen hubungan badan) dengan konteks yang diusung al-Qur'an; eliminasi perbudakan dengan menggauli budak sebagai konsekuensi pelembagaan perbudakan, yang dipahami sebagai pijakan penting oleh Syahrur untuk merekontekstualisasi dan merelevansikan al-Qur'an sebagai konsekuensi dari sifat kemenyeluruhan al-Qur'an (syumuliyyah) terlihat mengabaikan nilai kemaslahatan yang dibawa al-Qur'an. Bahkan, pola akomodasi nashberbasis mashlahat terhadap 'urf juga tidak dijadikan pijakan paradigmatiknya. Sehingga, reinterpretasi terhadap nashmenghasilkan produk hukum yang tampak mendekonstruksi ground norm al-Qur'an yang mengandung nilai kemaslahatan tinggi. Karena faktanya, tradisi komitmen hubungan badan; (urf khash) yang hanya berlaku di dunia barat, yang dilegitimasi oleh Syahrur sebagai tradisi yang tercakup dalam nash milkul yamin bertentangan dengan urf amm karena tidak semua negara di dunia melegalkan hal yang demikian. Oleh karena itu, upaya legitimasi Syahrur tersebut tidak memenuhi standar 'urf; harus diterima akal sehat, dan standarisasi mashlahat dalam hukum Islam sebagaimana yang digagas oleh al-Buthi.

Demi merealisasikan mashlahat dalam nashdan untuk menghindari ketertundukan fikih terhadap realitas, ijtihad istishlahy adalah keniscayaan yang idealnya digunakan oleh mujthahid. Dengan begitu, standar pertimbangan mashlahat dalam mengkaji fenomena adalahmashlahat dalam nashyang tentu telah berelevansi dengan kognisi sosial, bukan standar mashlahat yang hanya menguntungkan tradisi lokalitas tetapi mendekonstruksi nilai asas al-Qur'an. Akan menjadi sebuah produk hukum yang terlihat absurd ketika berupaya melegitimasi fenomena sosial yang berpijak pada nashtetapi paradigma yang terbangun dan produk hukumnya justru mencederai nash dengan mendekonstruksi objektivikasi nash yang sistematis.Menghindari ketidakberdayaan fikih terhadap realitas akan 
semakin terlihat jelas ketika proses produksi hukum mendialektikan mashlahah dengan 'urf yang eksis. Melalui langkah-langkah yang strategissistematis-verfikatif, produk hukum yang mewujud akan menjadi regulasi yang mengimbangi realitas dengan menjunjung tinggi norma, etik atau moral, serta hak asasi manusia secara general.

Jadi, penafsiran ayat-ayat milkul yamin pada tidak bisa dipaksakan untuk dihidupkan kembali hanya dengan orientasi syumuliyyah alQur'an.Jika memang realitas eksis tidak bisa diakomodir karena kecacatan kualifikasi nassh, maka upaya rekontekstualisasi ayat-ayat milkul yamin adalah kecacatan paradigma ijtihad. Dengan pertimbangan ini, maka hukum Islam yang tebangun dengan parameter mashlahah dan 'urf yang berelvansi dengan nashakan menentukan langkahnya untuk membangun peradaban Islam setiap saat tanpa harus mendekontruksi bangunan norma dalam nash. 


\section{DAFTAR PUSTAKA}

Abu Sunah, Ahmad Fahmi, al- 'Urf wa al- 'Adah fi Ra'yi al-Fuqaha, Mesir: Maktabah alAzhar, 1947.

Anshari Nasution, Ahmad Sayuti, "Perbudakan Dalam Hukum Islam”, Ahkam, Vol. 15, Nomor 1 Januari 2015.

Asmawi, “Konseptualisasi Teori Mashlahah", Salam, Vol. 1, Nomor 2 November 2014.

Auda, Jasser, Maqashid al-Shariah As Philosophy of Islamic Law: A Systems Approach, London: IIITT, 2008.

Buthi, Said Ramadhan al-, Dhawabitu al-Mashlahah fi asy-Syari'ah al-Islamiyyah, (Damaskus: Dar al-Fikr, 2005.

Fanani, Muhyar. "Pemikiran Muhammad Syahrur dalam Ushul Fih," Disesrtasi Dokor Universitas Islam Negeri Sunan Kalijaga Yogayakarta, 2005.

Ibnu 'Asyur, Muhammad at-Thahir, Maqashid asy-Syari'ah al-Islamiyyah li Muhammad at-Thahir Ibnu 'Asyur, tt:tt, 2005.

Jum’ah, ‘Ali, Tarikh Ushul al-Fiqh, Kairo: Dar al-Muqatham, 2015.

M. Noor Harisuddin, “Urf Sebagai Sumber Hukum Islam (Fiqh) Nusantara”, Al-Fikr, Vol. 20:1, 2016.

Mustaqim, Abdul, "Teori Hudud Muhammad Syahrur dan Kontribusinya dalam Penafsiran al-Qur'an”, al-Quds, Vol. 1 Nomor 12017.

Qaem Aulassyahied, "Studi Kritis Konsep Sunnah Muhammad Syharur," Kalimah, Vol. 13, Nomor 1 Maret 2015.

Qal'ah Ji, Muhammad Rowas, Mausu'ah Fiqh Umar bin Ibnu al-Khattab, Beirut: Dar anNafais, 1989.

Qaradhawi, Yusuf, Membumikan Hukum Islam: Keluasan dan Keluwesan Syari'at Islam Untuk Manusia, alih bahasa Ade Nurdin dan Riswan, Bandung: Penerbit Mizan.

Quraish Shihab, Tafsir al-Misbah: Pesan, Kesan, dan Keserasian al-Qur'an, Tangerang: Lentera Hati, 2009.

Raisuni, Ahmad ar- dan Muhammad Jamal Barut, al-Ijtihad: an-Nash, wa al-Waqi, wa alMashlahah, Damaskus: Dar al-Fikr, 2000. 


\section{Muhammad Syahrur Dan Konsep Milkul Yamin}

Sakirman, "Contemporary Fiqh Methodology in The Theory of The Limitation of Dialectisc Space and Time According To Muhammad Syahrur", Hunafa, Vol. 14: 2 Desember 2017.

Sarjana, Sunan Autad, "Konsep 'Urf dalam Penetapan Hukum Islam,” Tsaqafah, Vol. 13 Nomor 2 November 2017.

Syafiq, Ahmad, ar-Riqqu Fi al-Islam, alih bahasa Ahmad Zaki, Al-Jazirah: Maktabah anNafizah, 2010.

Syahrur, Muhammad, al-Kitab wa al-Qur’an, (Damaskus: al-Ahali, 1990).

, Nahwu Ushul Jadidah lil Fiqh al-Islamy: Fiqhu al-Mar'ah, Damaskus: al-Ahali, 2000.

, The Qur'an, Morality and Critical Reason: The Essential Muhammad Shahrur, alih bahasa Andreas Christman, Leiden: Brill, 2009.

Tarlam, Alam, "Analisi dan Kritik Metode Hermeneutika al-Qur'an Muhammad Syahrur,” Empirisma, Vol. 24, Nomor 1 Januari 2015.

Tarmininy, Abdus as-Salam at-, ar-Riqqu: Madhihi wa Hadhiruhu, tt:tt, tt.

Ulwan, Abdullah Nashih, Nidzhamu ar- Riq Fi al-Islam, Kairo: Dar as-Salam, tt.

Wahab Khalaf, Mashadir al-Tashri`al-Islamiy fi Ma La Nasha Fih, (Kuwait: Dar alQalam, 1972).

Wathani, Syamsul, "Kritik Salim al-Jabi atas Hermeneutika Muhammad Syahrur," elUmdah, Vol. 1, Nomor 2 Desember 2018.

Zuhaili, Wahbah, al-Fiqhu al-Islami wa Adillatuhu, Damaskus: Dar al-Fikr, 1986.

Zuhaili,Wahbah, at-Tafisr al-Munir: Fi al-'Aqidah wa asy-Syari'ah wa al-Manhaj, Damaskus: Dar al-Fikr, 2009. 